\title{
¿Usamos las mascarillas correctas para la COVID-19?
}

Do we use the right masks for COVID-19?

Juan José Agún González¹ (i) 0000-0002-2677-7198

Raúl Aguilar-Elena ${ }^{1}$

${ }^{1}$ Universidad Internacional de Valencia, Valencia, España.

Fechas · Dates

Recibido: 2021.02.13

Aceptado: 2021.03.29

Publicado: 2021.04.15
Correspondencia · Corresponding Author

Juan José Agún González juanjose.agun@campusviu.es 
Sra. directora:

Desde la declaración de la pandemia y el estado de alarma el pasado 14 de marzo de 2020 la mayoría de los Estados han promovido el uso de las mascarillas como un elemento preventivo básico (junto con la higiene de manos y el mantenimiento de las distancias de seguridad), siendo muy importante garantizar que las mascarillas utilizadas sean las adecuadas.

Si contextualizamos en el ámbito laboral encontramos que, en Europa, el Reglamento (UE) 2016/425 del Parlamento Europeo y del Consejo establece los requisitos sobre el diseño y la fabricación de los Equipos de Protección Individual (EPI) para garantizar la protección de la salud y la seguridad de los usuarios y establecer las normas relativas a la libre circulación de los EPIs en la Unión. En el caso de las mascarillas filtrantes de protección contra partículas, el cumplimiento de la norma armonizada ${ }^{(1)}$ EN 149:2001+A1:2009, citada en el Diario Oficial de la Unión Europea (2018C 113/03) y (2018/C 209/03) dando presunción de conformidad con el citado reglamento y sobre la publicación de títulos y referencias de normas armonizadas conforme a la legislación sobre armonización de la Unión, respectivamente.

Esta norma clasifica en tres posibles niveles a las mascarillas filtrantes de protección contra partículas (FPP: acrónimo de Filtering Face Piece), en función de su rendimiento o eficacia de filtración y de su fuga hacia el interior: FFP1 (rendimiento de $78 \%$ y porcentaje de fuga de $22 \%$ ), FFP2 (rendimiento de $92 \%$ y porcentaje de fuga de $8 \%$ ) y FFP3 (rendimiento de $98 \%$ y porcentaje de fuga de $2 \%$ ). Por lo tanto, las mascarillas FFP1 no se recomiendan para Covid-19, mientras que las FFP2 / FFP3 se recomiendan para la protección eficaz ${ }^{(2)}$ frente a la COVD-19.

Uno de los problemas que hemos sufrido los profesionales durante la primera ola de la pandemia fue una situación extraordinaria de escasez de equipos con el marcado CE reglamentario en base a normas armonizadas por lo que, considerando esta situación, el gobierno tomó la decisión de aceptar de forma temporal otra serie de equipos EPI sin el marcado CE reglamentario en base a normas armonizadas ${ }^{(3)}$. Esta decisión ha dado entrada a numerosas falsificaciones y EPIs de escasa o nula eficacia.

La realidad actual es que nos encontramos con la obligación de la aplicación del R.D. 773/1997 sobre disposiciones mínimas de seguridad y salud relativas a la utilización por los trabajadores de EPIs (Categoría III) y con mascarillas certificadas por algunos Organismos Notificados (ON) europeo con los ensayos correspondientes a los módulos B y C2 realizados por laboratorios chinos no acreditados para la EN 149:2001+A1:2009, es decir sin ensayos propios del ON o copias literales de las pruebas chinas, en muchas ocasiones mascarillas KN95 ahora certificadas como FFP2, generando reticencias o dudas sobre su eficacia. 
Por lo tanto, en el escenario actual tenemos principalmente las siguientes posibilidades:

- Mascarillas KN95 con modelos falsos ${ }^{(4)}$, no válidos o ni siquiera homologados por la propia norma china. Está prohibida su venta desde el 01/01/2021, pero se continúan vendiendo.

- Mascarillas higiénicas y caseras que NO son un equipo de protección ${ }^{(5)}$ individual y, por lo tanto, no protegen al portador.

- Mascarillas quirúrgicas, muchas con un parecido razonable a las quirúrgicas, pero sin la certificación UNE EN 14683:2019+AC:2019.

- Mascarillas FFP2 y FFP3 de fabricación y ensayos chinos y homologación por ON europeo sin ensayos realizados por los dichos organismos o copias literales de los ensayos chinos, en ocasiones convirtiendo KN95 en FFP2, pese a las diferencias de exigencias legales de las pruebas.

- Por último, y las más difíciles de encontrar, las mascarillas FFP2 y FFP3 que cumplen con todos los requisitos de la norma, certificados y ensayados por un ON europeo.

A la vista de esta situación y analizado el escenario actual y futuro, podríamos variar la pregunta inicial ¿usamos las mascarillas correctas para la COVID-19? por otras dos: ¿disponemos de mascarillas adecuadas para protegernos de la COVID-19? ¿Hemos consultado a los profesionales expertos en esta materia (Técnicos de Prevención de Riesgos Laborales) sobre los equipos de protección que tenemos que utilizar?

Una cosa está clara, con el difícil panorama que nos espera para los próximos meses es necesario contar con todos los medios humanos y materiales a nuestro alcance para acabar con esta pandemia.

\section{Bibliografía}

1. Norma UNE-EN 149:2001+A1:2010 Dispositivos de protección respiratoria. Medias máscaras filtrantes de protección contra partículas. Requisitos, ensayos, marcado.

2. Procedimiento de actuación para los servicios de prevención de riesgos laborales frente a la exposición al SARS-Cov-2. (tabla 2 componentes del equipo de protección individual recomendados para la protección frente al nuevo coronavirus SARS-COV-2). Ministerio de Sanidad. https://www.mscbs.gob.es/profesionales/ saludPublica/ccayes/alertasActual/nCov/documentos/Proteccion_Trabajadores_SARS-CoV-2.pdf

3. Resolución de 23 de abril de 2020, de la Secretaría General de Industria y de la Pequeña y Mediana Empresa, referente a los equipos de protección individual en el contexto de la crisis sanitaria ocasionada por el COVID-19. BOE, n 115, de 25 de abril de 2020. 
4. ALERTA INVASSAT Equipos de protección individual frente COVID-19: mascarillas no conformes 15/01/2021. (Consultado el 28/01/2021). Disponible en: http://invassat.gva.es/documents/161660384/171645761/AL01-210102+Equipos+de+protección+individual+frente+COVID-19+-+mascarillas+no+conformes+15.01.2021/66f55c7c-d22b-4d59-bd3e-ef16d2ee590c

5. ¿Qué debes tener en cuenta al comprar una mascarilla? Ministerio de Consumo. (Consultado el 28/01/2021). Disponible en: https://www.mscbs.gob.es/en/profesionales/saludPublica/ccayes/alertasActual/nCov/documentos/030520_GUIA_ COMPRA_MASCARILLAS.pdf 